\title{
Analysis Accidents Detection
}

\author{
Tanisha Sonawane $^{1}$, Siddhi Bhamare ${ }^{2}$, Mayuri Gote ${ }^{3}$, Ujjwala Wale ${ }^{4}$, Prof. M.K.Nivangune ${ }^{5}$ \\ Student, Comp Dept, Stes Sinhgad Academy of Engineering Kondhwa, Pune, India ${ }^{1,2,3,4}$ \\ Guide, Comp Dept, Stes Sinhgad Academy of Engineering Kondhwa, Pune, India
}

\begin{abstract}
Road accidents are increasing now-a-days. It causes a loss of life of people to the huge amount. There are many reason with result in road accident. The rapid development in urban, industrial parts and migration along with other social changes have found in increasing necessity for travel across all age groups in the entire country. Accident is an event, occurring suddenly, unexpectedly and in any situation under unforeseen conditions. An accident that takes place on the road involving a vehicle is termed as road traffic accident. With poor public transportation systems and inability of people to buy cars, the personal modes of transport have increased across Indian cities and in rural areas. This increasing importance on motor vehicles and motorcycles has also started influencing health of people in a significant way. Road traffic injuries are predicted to rise from ninth place in 2004 to fifth place by 2030 as contributor to the global burden of disease. Each year, road traffic injuries take the lives of 1.2 million people around the world and seriously harms millions more.
\end{abstract}

Keywords: Roadway Fatal Accidents, Association, Classification, Clustering

\section{INTRODUCTION}

Road accident is most un sudden thing to happen to a road user, people though they happen quite often. The most realistic thing is that we don't learn from our mistakes on road. Most of the road users ,people are quite well known of the general rules, regulation and safety measures while using roads but it is only the laxity on part of road users, which cause accidents and crashes. Main cause of accidents and crashes on the road are due to human mistakes. We are mentioning the some of the common behaviour of humans which results in accident.

1. Over Speeding Driving

2. Drunken Driving

3 .Distractions to Driver

4. Red light Jumping

5. Avoiding Safety precautions like Seat belts and Helmets

6.Non-adherence to lane driving and overtaking in a wrong way.

The classic Apriori algorithm which is used for the frequently addressed item sets. The algorithm uses the bottom up approach and thus the frequently occurring subsets extended one at a time. The vast amount of data is classified into the clusters by making the use of k-means algorithm.

\section{LITERATURE SURVEY}

"Research and implement of traffic accident analysis system based on accident black spot ."[1]

After dealing and analyzing of the urban road traffic accident, research out the model of accident black spot clustering based on GIS, made the framework of analysis system and accident management of spatial visualization that GIS based, achieved the system that can analyzed accident data and display the result graphically

\section{"Automobile black box system for accident analysis."[2]}

Automobiles and computing technologies are creating a new level of data services in vehicles. The Automobile Black Box has functions similar to an airplane black box. It is used to analyzed the cause of vehicular accidents and prevent the loss of life and property arising from vehicle accidents. This paper proposes a prototype of an Automobile Black Box System that can be installed into vehicles. The system aims to achieve accident analysis by objectively tracking what occurs in vehicles. The system also involves enhancement of security by preventing tampering of the Black Box data. In addition, the Black Box sends an alert message to a pre-stored mobile number via Short Message Service (SMS) in the case of occurrence of an accident. The proposed system makes use of 12 sensors to record the various driving data parameters. The Raspberry Pi controller (RPi) and Arduino controllers are used to regulate these sensors. The data received from the sensors are stored on the SD card mounted on RPi for retrieval after the accident. The system uses external sensors such as camera and Global Positioning System (GPS) to collect video and location data. 
Vol. 8, Issue 5, May 2019

“Accident analysis, related to the train movement in a track section in ŽSR conditions."[3]

The main subject of this paper is the accident analysis and its resulting analysis of the consequences of every single hazard, related to the train movement in a track section and the calculation (estimation) of risk that is connected to the hazard consequences in the form of human casualties. In the paper, the assessment of the risk according to statistical data of accident analysis made by the Slovak Railways (Železnice Slovenskej Republiky, ŽSR) is shown. The paper deals also with the assessment task of the human casualties.

\section{PROPOSE SYSTEM}

In Proposed system we are analysing the fatal road accidents which may happens due following Reasons:

1. Potholes

2. Light intensity

3. Weather condition

4. Speed limit

5. Alcohol

Potholes - Due to the rains and oil spills potholes are generated which will cause the accidents. The potholes are detected and its height, depth and size are measured using ultrasonic sensor. The GPS is used to find the exact location of pothole.

Light intensity - An LDR is a component that has a function of resistance that changes with the light intensity that falls upon it. And this allows them to be used in light sensing circuits.

Weather condition-The surface temperature sensors are well known and use for many applications including, pipe temperature monitoring, solar panel temperature, water tanks, control panels, battery monitoring, and many others. Proper siting for weather sensors is important to ensure accurate readings.

Speed limit - A Hall effect sensor is a device that is used to measure the magnitude of a magnetic field.. Hall effect sensors are used for proximity sensing, positioning, speed detection, and current sensing applications.

Alcohol - An alcohol sensor detects the attentiveness of alcohol gas in the air and an analog voltage is an output reading. The sensor can be use and activate at temperatures ranging from -10 to $50^{\circ} \mathrm{C}$ with a power supply which is less than $150 \mathrm{Ma}$ to $5 \mathrm{~V}$.

From all these parameters we are plotting graph according to analyse data to show the roads having high possibilities of accidents.

\section{SYSTEM ARCHITECTURE}

Following diagram is our system's architecture diagram:

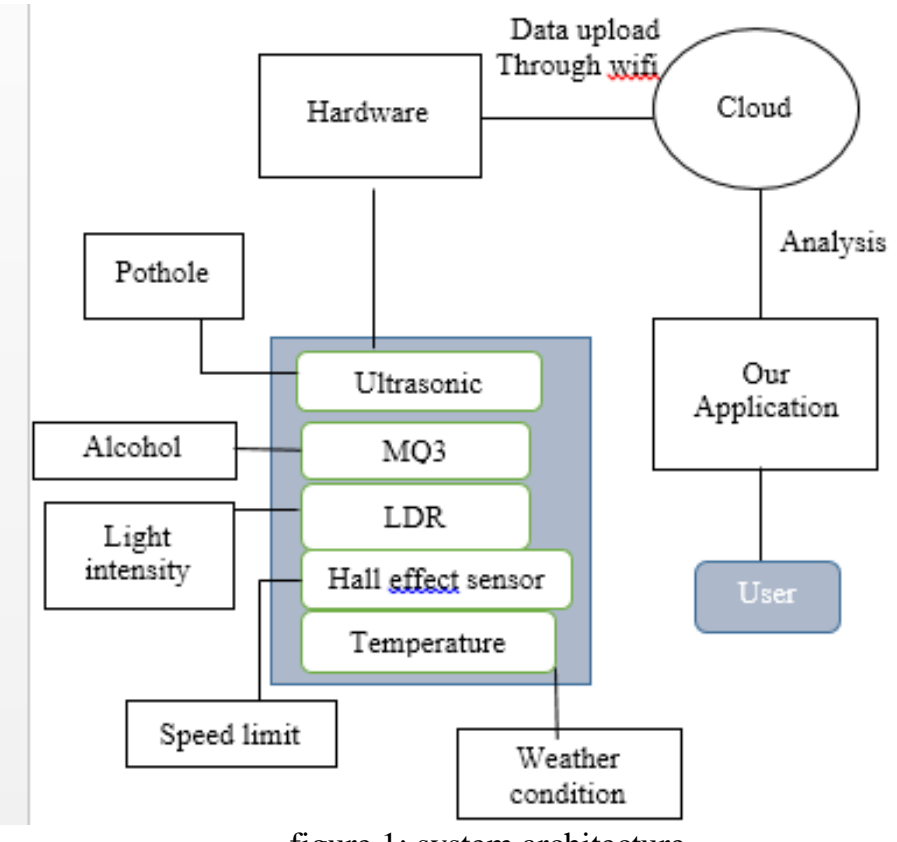

figure 1: system architecture 


\title{
International Journal of Advanced Research in Computer and Communication Engineering
}

\author{
Vol. 8, Issue 5, May 2019
}

In this system we are taking input from hardware like sensors, controllers. The data collected by hardware get uploaded through Wi-Fi on cloud. After analysing uploaded data user can see the graph according to area or roads.

\section{METHODOLOGIES}

To achieve the objectives a methodology is to be done. Accident data is collected from different area and accident prone stretches on the area. Accident models will be developed considering various factors. For this work study area is to be identified for collecting the required information details. We are going to use sensors, controllers and Wi-Fi. Therefore the study consisted of information of Arduino, controllers, Wi-Fi and data mining and storage with different types of algorithms related to data mining for analysis of large collected data from sensors. The ESP8266 Wi-Fi Module is a self-contained SOC with integrated TCP/IP protocol stack that can give any microcontroller access to your Wi-Fi network. The ESP8266 has the capacity of either hosting an application or offloading all Wi-Fi networking functions from another application processor.

The ESP8266 module is an more cost effective board with a many, and ever growing, community. This module has a powerful enough on-board processing capacity and storage capacity that allows it to be integrated with the sensors, other application specific devices through its GPIOs with minimum development up-front and minimum loading during runtime. Its high degree of on-chip integration allows for minimum external circuitry, including the front-end module, is designed to occupy minimum PCB area. The ESP8266 supports APSD for VoIP applications. Arduino is an opensource platform that is used for developing electronics projects. Arduino consists of a physical programmable circuit board that is often referred to as a microcontroller and a piece of software, or IDE (Integrated Development Environment) that runs on your computer that is used to write and upload computer code to the physical board. Arduino provides a good standard form factor that breaks out the functions of the micro-controller into a more and more accessible package.

Prediction in data mining is to determine data points purely on the information of another related data value. It is not important related to future events but the used variables are unknown. Predictive modelling is a process/ function that uses data mining and probability to forecast outcomes. Each model is made up of a many number of predictors, which are variables that are likely to influence future outcome. Once data has been collected for relevant predictors, a statistical model is produced and formulated. Cloud storage is a model called as cloud computing model in which data is stored on remote servers accessed from the internet, or "cloud." It is maintained, operated and managed by a cloud storage service provider on a storage servers that are developed on virtualization techniques. Apriori algorithm is an algorithm that is use for frequent item set mining and association rule learning applied on transactional databases. It proceeds by determining the frequent individual items in the database and enlarging them to larger and larger item sets as long as those item sets appear sufficiently often in the database. The frequent item sets identify by Apriori algorithm can be used to determine association rules which mention general trends in the database: this has applications in domains such as market basket analysis.

\section{ADVANTAGES}

- We can easily identify roads or area having high possibilities of fatal accidents.

- To identify easily the place at which accidents happens due to high Light intensity, high speed, weather conditions and drunk drive detection

- We are providing system to analyse the four conditions in one system

- It will help to minimize the road fatal accidents

\section{CONCLUSION}

Road accident issues in the country is a matter of great concern. The number of accident fatalities is increasing every year due to overtaking and over speeding on all types of roads, overloading of commercial vehicles. The data was analyzed to determine the cause /characteristics of accidents. This paper has focused some algorithm on all techniques of data mining that can be applied on IOT. In this system we are getting threshold values of parameters like Light intensity, high speed, weather conditions and drunk drive detection. Existing scenario is we need to get data separately for each condition after that we analyse that data and then get separate result for each conditions. So we minimizes our work developing one system to analyse the data of causing accidents. 
International Journal of Advanced Research in Computer and Communication Engineering

Vol. 8, Issue 5, May 2019

VIII. RESULT

\section{Accident Analysis}

\section{3:09 PM}

…

AccidentAnalysis

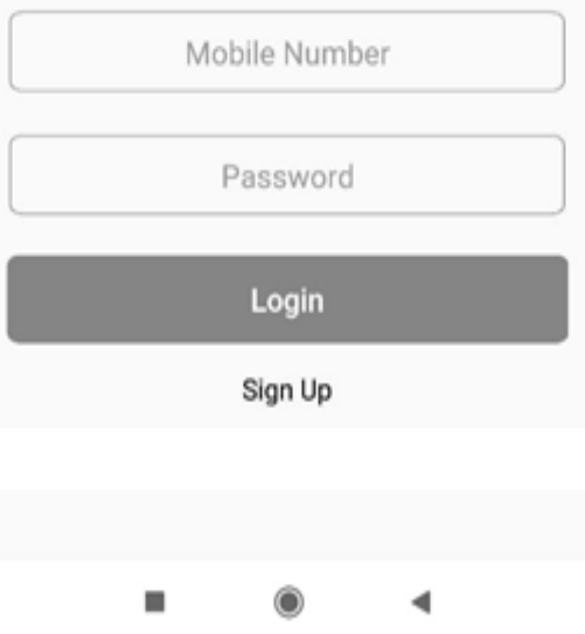

3:09 PM

AccidentAnalysis

Fmail Id

Mobile Number

Password

Conform Password

Sign Up

Already have an account?

Login

- 


\section{International Journal of Advanced Research in Computer and Communication Engineering}

Vol. 8, Issue 5, May 2019
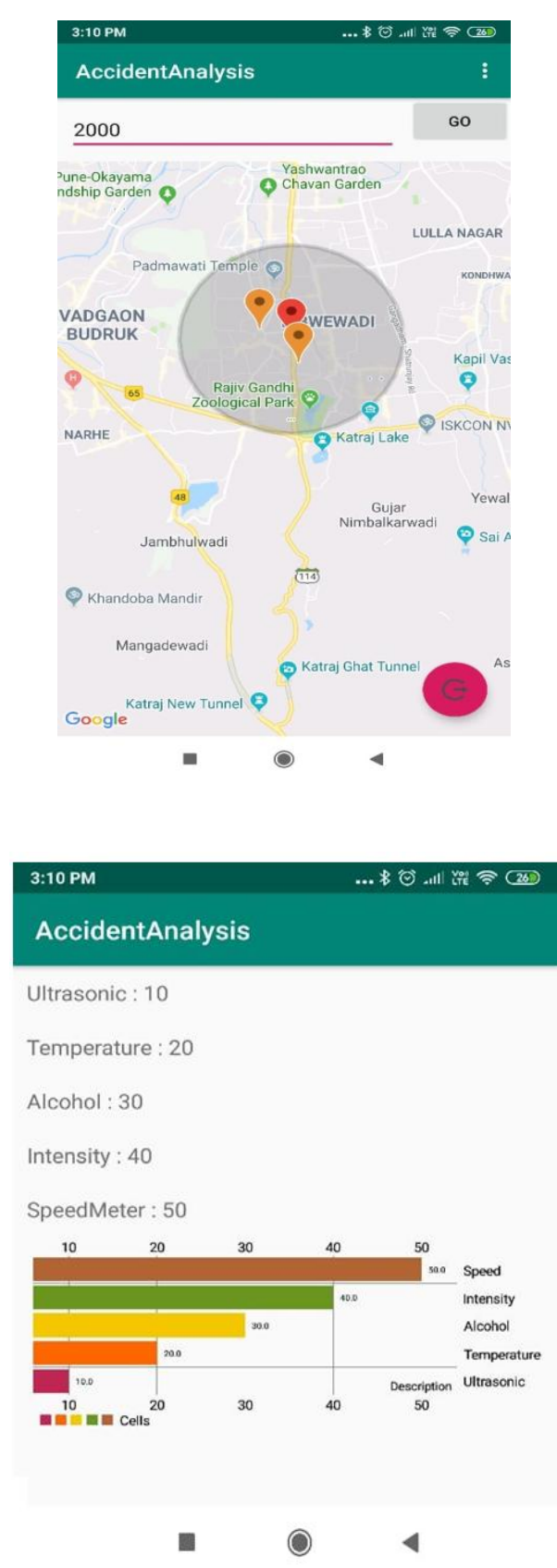

\section{REFERRENCES}

[1]. Liling Li, Sharad Shrestha, Gongzhu Hu,” Analysis of Road Traffic Fatal Accidents Using Data Mining Techniques”, IEEE, 03 July 2017, DOI 10.1109/SERA.2017.7965753.

[2]. Amira A El Tayeb, Vikas Pareek, and Abdelaziz Araar. Applying association rules mining algorithms for traffic accidents in dubai. International Journal of Soft Computing and Engineering, September 2015.

[3]. R. V. Ponnaluri, "Road traffic crashes \& risk groups in India: analysis, interpretations, \& prevention strategies", IATSS Research, 35(2), 2012.

[4]. MORTH, 2014. "Road Accidents in India 2013", New Delhi: Ministryof Road Transport and Highways Transport Research Wing, Government of India. August 2014.

[5]. R. Bandyopadhyaya, and S. Mitra, "Modelling Severity Level in Multivehicle Collision on Indian Highways", Procedia - Social and Behavioral Sciences, 104, 1011-1019, 2013.

[6]. A. N. Dehury, A. K. Patnaik, A. K. Das, U. Chattraj, P. Bhuyan, M. Panda "Accident Analysis and Modeling on NH-55(India)" International Journal of Engineering Inventions, eISSN: 2278-7461, p-ISSN: 2319-6491, Volume 2, Issue 7 (May 2013) PP: 80-85

[7]. Gogineni Divya, Yenumula Anand Babu ,p.gopi "Highway Accident Modeling Influence of Geometrics" international journal and magazine of engineering, technology, management and research, issn NO.2348-4845, volume no.3(2016), issue NO.10(October 2016) of scientific \& technology research ISSN NO.2277-8616, volume 2, issue 2, february 2013 